\title{
Article \\ Acrylamide Elimination by Lactic Acid Bacteria: Screening, Optimization, In Vitro Digestion and Mechanism
}

\author{
Amal S. Albedwawi ${ }^{1}$, Reem Al Sakkaf ${ }^{2}$, Ahmed Yusuf ${ }^{2}{ }^{(D}$, Tareq M. Osaili $^{3,4}$, Anas Al-Nabulsi ${ }^{4}$, \\ Shao-Quan Liu ${ }^{5}$, Giovanni Palmisano ${ }^{2}$ (D) and Mutamed M. Ayyash ${ }^{1, *(D)}$
}

\section{check for} updates

Citation: Albedwawi, A.S.; Al Sakkaf R.; Yusuf, A.; Osaili, T.M.; Al-Nabulsi, A.; Liu, S.-Q.; Palmisano, G.; Ayyash, M.M. Acrylamide Elimination by Lactic Acid Bacteria: Screening, Optimization, In Vitro Digestion and Mechanism. Microorganisms 2022, 10, 557. https://doi.org/10.3390/ microorganisms10030557

Academic Editor:

Antonio Bevilacqua

Received: 13 February 2022

Accepted: 1 March 2022

Published: 3 March 2022

Publisher's Note: MDPI stays neutral with regard to jurisdictional claims in published maps and institutional affiliations.

Copyright: () 2022 by the authors Licensee MDPI, Basel, Switzerland. This article is an open access article distributed under the terms and conditions of the Creative Commons Attribution (CC BY) license (https:// creativecommons.org/licenses/by/ $4.0 /)$.
1 Department of Food Science, College of Agriculture and Veterinary Medicine, United Arab Emirates University (UAEU), Al Ain P.O. Box 15551, United Arab Emirates; 201690240@uaeu.ac.ae

2 Department of Chemical Engineering, Center for Membrane and Advanced Water Technology (CMAT), Research and Innovation on $\mathrm{CO}_{2}$ and Hydrogen ( $\left.\mathrm{RICH}\right)$, Khalifa University of Science and Technology, Abu Dhabi P.O. Box 127788, United Arab Emirates; reem.alsakkaf@ku.ac.ae (R.A.S.); ahmed.yusuf@ku.ac.ae (A.Y.); giovanni.palmisano@ku.ac.ae (G.P.)

3 Department Clinical Nutrition and Dietetics, University of Sharjah, Sharjah P.O. Box 27272, United Arab Emirates; tosaili@sharjah.ac.ae

4 Department of Nutrition and Food Technology, Jordan University of Science and Technology, Irbid 22110, Jordan; anas_nabulsi@just.edu.jo

5 Department of Food Science and Technology, Faculty of Science, National University of Singapore, Singapore 117542, Singapore; fstlsq@nus.edu.sg

* Correspondence: mutamed.ayyash@uaeu.ac.ae roasting, frying, and grilling are cooking methods that cause its formation in the presence of reducing sugar and asparagine. To prevent acrylamide formation or to remove it after its formation, scientists have been trying to understand acrylamide formation pathways, and methods of prevention and removal. Therefore, this study aimed to: (1) screen newly isolated LAB for acrylamide removal, (2) optimize conditions ( $\mathrm{pH}$, temperature, time, salt) of the acrylamide removal for selected LAB isolates using Box-Behnken design (BBD), (3) investigate the acrylamide removal abilities of selected LAB isolates under the in vitro digestion conditions using INFO-GEST2.0 model, and (4) explore the mechanism of the acrylamide removal using scanning electron microscopy coupled with energydispersive X-ray spectroscopy (SEM-EDS), zeta potential, transmission electron microscopy (TEM) measurement, and Fourier transform infrared spectroscopy (FTIR). Forty strains were tested in MRS broth, where Streptococcus lutetiensis and Lactiplantibacillus plantarum had the highest capability of acrylamide removal by $39 \%$ and $26 \%$, respectively. To enhance the binding ability, both strains were tested under controlled conditions of $\mathrm{pH}\left(4.5,5.5\right.$ and 6.5), temperature $\left(32{ }^{\circ} \mathrm{C}, 37^{\circ} \mathrm{C}\right.$ and $\left.42{ }^{\circ} \mathrm{C}\right)$, time (14, 18 and $22 \mathrm{~h})$, and $\mathrm{NaCl}(0 \%, 1.5 \%$ and $3 \% w / v)$ using Box-Behnken design (BBD). Both strains removed more acrylamide in the range of $35-46 \%$ for S. lutetiensis and $45-55 \%$ for L. plantarum. After testing the bacterial binding ability, both strains were exposed to a simulated gastrointestinal tract environment, removing more than $30 \%$ of acrylamide at the gastric stage and around $40 \%$ at the intestinal stage. To understand the mechanism of removal, LAB cells were characterized via scanning electron microscopy coupled with energy-dispersive X-ray spectroscopy (SEM-EDS) and transmission electron microscopy (TEM) techniques. Cell charges were characterized by zeta potential and functional groups analyzed by Fourier transform infrared spectroscopy (FTIR). Results indicated that increasing cell wall thickness improved acrylamide adsorption capacity. Both FTIR and EDS indicated that functional groups $\mathrm{C}=\mathrm{O}, \mathrm{C}-\mathrm{O}$, and $\mathrm{N}-\mathrm{H}$ were associated with acrylamide adsorption.

Keywords: acrylamide; TEM; SEM-EDS; FTIR; Box-Behnken design; the reduction mechanism

\section{Introduction}

Acrylamide is a chemical compound that is formed in heated carbohydrate-rich food. It is known to be a neurotoxin carcinogen in animals and a probable carcinogen in humans [1]. 
In addition, toxicological studies have provided proof that acrylamide can be genotoxic, neurotoxic, and toxic to the reproductive system [2]. After the discovery of acrylamide formation in food during the Maillard reaction with the presence of reducing sugar and free asparagine [3], both the Food and Drug Organization/World Health Organization and European Food Safety Authority started scanning the products in the markets and published guidelines to minimize acrylamide risks $[4,5]$.

French fries, roasted coffee, potato chips, bread, pastries, breakfast cereals, and biscuits are some of the food types that might increase acrylamide intake [6]. Acrylamide is an unsaturated amide that can enter the body through food ingestion, inhalation of acrylamide that pollutes air, and skin contact. It is odorless, colorless, and highly soluble in water [2]. Since the discovery of acrylamide's risks and its occurrences in food, scientists have published studies on factors (e.g., $\mathrm{pH}$, temperature, $\mathrm{NaCl}$ ) and measures (e.g., changes in raw materials, changes in cooking or processing conditions, or cooking with the emerging techniques such as irradiation, ultrasound, microwave) to control and reduce acrylamide formation [7].

Several attempts have been made to mitigate acrylamide presence in food by reducing its formation or removing formed acrylamide [7]. For example, it has been reported that additions of salt $(\mathrm{NaCl})$, grape polyphenols extract, and $p$-coumaric acid-phosphate buffer to biscuits, potato chips, and fried potatoes, respectively, decreased acrylamide formation but changed the sensory characteristics of food [8-10]. Manipulating the food processing conditions (temperature, $\mathrm{pH}$, incubation time, vacuuming) to reduce acrylamide formation has also been reported [11].

A microbial approach has been presented to mitigate acrylamide presence $[7,12]$. Lactic acid bacteria Lacticaseibacillus casei was used to ferment mixed rye and removed up to $20.2 \%$ of acrylamide [13]. Other strains such as Pediococcus acidilactici in biscuit, Lactobacillus delbrueckii in fried potato and Lactobacillus casei Shirota in potato chips were employed to remove acrylamide in these products. the percentages of the acrylamide removal were $78 \%, 51 \%$, and $65-73 \%$, respectively [14-16]. Lactobacillus is a Grampositive, fermentative, facultatively anaerobic and non-sporeforming microorganisms. The family of Lactobacillaceae contains Lactobacillus, Paralactobacillus and Pediococcus genera [17].

The mechanism of acrylamide removal by microorganisms is not fully explored and understood [7]. The investigation of acrylamide removal by new microorganisms (such as lactic acid bacteria (LAB) and yeasts) is still highly sought, as suggested by various studies $[7,18]$. Moreover, it is crucial to investigate the acrylamide removal conditions $(\mathrm{pH}$, temperature, water activity) surrounding the microorganisms. To the best of our knowledge, no information is available regarding acrylamide removal by LAB under the in vitro digestion condition.

Therefore, this study aimed to: (1) screen newly isolated LAB for acrylamide removal, (2) optimize conditions $(\mathrm{pH}$, temperature, time, salt) of the acrylamide removal for selected $\mathrm{LAB}$ isolates using Box-Behnken design (BBD), (3) investigate the acrylamide removal abilities of selected LAB isolates under the in vitro digestion conditions using the INFOGEST2.0 model, and (4) explore the mechanism of the acrylamide removal using scanning electron microscopy coupled with energy-dispersive X-ray spectroscopy (SEM-EDS), zeta potential, transmission electron microscopy (TEM) measurement, and Fourier transform infrared spectroscopy (FTIR).

\section{Materials and Methods}

All chemicals were purchased from Sigma-Aldrich (St. Louis, MO, USA) unless otherwise is mentioned.

\subsection{Strains of Bacteria}

Forty strains of LAB previously isolated from food products in our laboratory [19-21] were assessed for their ability to eliminate acrylamide. All isolates were kept at $-20{ }^{\circ} \mathrm{C}$ in $50 \%$ 
glycerol as a stock. These isolates were identified and classified under the following genera: (1) Enterococcus; (2) Pediococcus; (3) Bifidobacterium; (4) Lactobacillus; and (5) Streptococcus. All cultures were activated twice in de Man, Rogosa, and Sharpe (MRS) broth (LAB-M, Neogen Culture Media, Heywood, UK) by inoculating a loopful of the bacterial stock into $10 \mathrm{~mL}$ of MRS broth followed by incubation at $37^{\circ} \mathrm{C}$ for $20 \mathrm{~h}$.

\subsection{Preparation of Stock and Working Solutions of Acrylamide}

An acrylamide stock solution was prepared by dissolving $50 \mathrm{mg}$ of powdered acrylamide (Sigma Chemical Co., St. Louis, MO, USA) in deionized water using a $50 \mathrm{~mL}$ volumetric flask to obtain a concentration of $1 \mathrm{mg} / \mathrm{mL}$. Two working solutions were prepared by diluting the stock solution to obtain $50 \mu \mathrm{g} / \mathrm{mL}$ and $100 \mu \mathrm{g} / \mathrm{mL}$ in $10 \mathrm{~mL}$ of MRS broth in the screening stage.

\subsection{Acrylamide Binding Assay_Preliminary Screening for Media Components and Bacterial Cultures}

Ten milliliters of sterilized MRS broth supplemented with acrylamide at concentrations of $50 \mu \mathrm{g} / \mathrm{mL}$ or $100 \mu \mathrm{g} / \mathrm{mL}$ were inoculated with $1 \%$ of an activated culture followed by incubation at $37^{\circ} \mathrm{C}$ for $20 \mathrm{~h}$. Afterward, bacterial enumeration was performed by a pourplate method using MRS agar followed by anaerobic incubation at $37{ }^{\circ} \mathrm{C}$ for $20 \mathrm{~h}$. To prepare the samples for acrylamide analysis by LC-MS-MS, bacterial cells were removed by centrifugation $(10,000 \times g, 10 \mathrm{~min})$. The supernatants were collected for acrylamide analysis. Each sample was analyzed in duplicate, and for each group of samples, there were controls of MRS broth, MRS with bacteria, and MRS spiked with acrylamide.

\subsection{Optimization of Acrylamide Removal Using Box-Behnken Design}

Box-Behnken design (BBD) was employed to optimize the four variables at three levels each: $\mathrm{pH}\left(4.5,5.5\right.$ and 6.5) using $1.0 \mathrm{~N} \mathrm{HCl}$ or $1.0 \mathrm{M} \mathrm{NaOH}$, temperature $\left(32{ }^{\circ} \mathrm{C}\right.$, $37^{\circ} \mathrm{C}$ and $\left.42^{\circ} \mathrm{C}\right)$ using anaerobic incubators, incubation period $(14,18$ and $22 \mathrm{~h}), \mathrm{NaCl}$ $(0 \%, 1.5$ and $3 \% w / v)$. Minitab v.21 was used to construct the experimental design and perform statistical analysis. The four independent variables were investigated with 27 experimental runs and three repetitive central points. The experiments were conducted for two different strains of LAB under aerobic and anaerobic conditions. Each experiment was carried out in triplicate, as presented in Tables 1 and 2 . The polynomial equation is presented as follows:

$$
Y=\beta_{0}+\sum \beta_{i} X_{i}+\sum \beta_{i i} X_{i}^{2}+\sum \beta_{i j} X_{i} X_{j}
$$

where $\mathrm{Y}$ is the predicted acrylamide concentration or bacterial count, and $\mathrm{X}_{\mathrm{i}}$ and $\mathrm{X}_{\mathrm{j}}$ are the independent variables. The studied variables were $\mathrm{pH}$, temperature, time, and $\mathrm{NaCl}$. $\beta_{\mathrm{o}}$ is the regression coefficient of the model and $\beta_{\mathrm{i}}, \beta_{\mathrm{ii}}$, and $\beta_{\mathrm{ij}}$ are the linear, quadratic and interaction coefficients, respectively. To investigate the relationship between the independent variables and the responses, two-dimensional response surface plots were constructed. The corresponding $p$-values from the ANOVA results were used to evaluate the significance.

The microbial population was measured by optical density at $600 \mathrm{~nm}$ with a spectrophotometer in 24-well plates using an Epoch 2 Microplate Spectrophotometer from BioTeck, Santa Clara, CA, USA. After the determination of bacterial populations, the samples were collected in $1.5 \mathrm{~mL}$ tubes and centrifuged at $10,000 \times g$ for $10 \mathrm{~min}$. The supernatants were collected for further analysis for acrylamide using Agilent Technologies 6495 Triple Quad LC-MS-MS (Santa Clara, CA, USA). 
Table 1. Box-Behnken experimental design with coded variables and the responses of acrylamide removal (\%) for S. lutetiensis and L. plantarum under anaerobic condition.

\begin{tabular}{|c|c|c|c|c|c|c|}
\hline \multirow{2}{*}{ Runs } & \multirow{2}{*}{ Temperature $\left({ }^{\circ} \mathrm{C}\right)(\mathrm{X} 1)$} & \multirow{2}{*}{$\mathrm{pH}(\mathrm{X} 2)$} & \multirow{2}{*}{ Time (h) (X3) } & \multirow{2}{*}{$\mathrm{NaCl}(\mathrm{g} / 100 \mathrm{~mL})(\mathrm{X} 4)$} & \multicolumn{2}{|c|}{ (\%) Growth } \\
\hline & & & & & S. lutetiensis & L.plantarum \\
\hline 1 & 42 & 6.5 & 18 & 0.0 & 17.6 & 52.9 \\
\hline 2 & 42 & 5.5 & 18 & 1.5 & 35.1 & 53.7 \\
\hline 3 & 42 & 5.5 & 14 & 1.5 & 24.8 & 56.2 \\
\hline 4 & 37 & 6.5 & 18 & 1.5 & 21.4 & 8.0 \\
\hline 5 & 37 & 5.5 & 22 & 0.0 & 12.9 & 15.5 \\
\hline 6 & 32 & 5.5 & 22 & 1.5 & 25.7 & 16.8 \\
\hline 7 & 37 & 4.5 & 14 & 3.0 & 24.4 & 20.0 \\
\hline 8 & 37 & 4.5 & 18 & 1.5 & 35.8 & 24.7 \\
\hline 9 & 42 & 5.5 & 18 & 1.5 & 28.8 & 54.0 \\
\hline 10 & 37 & 5.5 & 18 & 0.0 & 27.6 & 34.6 \\
\hline 11 & 37 & 5.5 & 14 & 1.5 & 33.6 & 45.0 \\
\hline 12 & 32 & 6.5 & 18 & 3.0 & 21.8 & 8.3 \\
\hline 13 & 37 & 6.5 & 22 & 1.5 & 24.9 & 42.5 \\
\hline 14 & 37 & 6.5 & 14 & 1.5 & 35.0 & 39.7 \\
\hline 15 & 37 & 5.5 & 18 & 0.0 & 33.6 & 43.0 \\
\hline 16 & 32 & 5.5 & 18 & 0.0 & 46.5 & 7.9 \\
\hline 17 & 37 & 6.5 & 18 & 0.0 & 27.5 & 41.0 \\
\hline 18 & 37 & 5.5 & 14 & 3.0 & 25.4 & 35.5 \\
\hline 19 & 42 & 4.5 & 18 & 3.0 & 27.3 & 55.5 \\
\hline 20 & 32 & 5.5 & 14 & 1.5 & 33.6 & 9.3 \\
\hline 21 & 37 & 4.5 & 18 & 1.5 & 30.0 & 38.5 \\
\hline 22 & 37 & 5.5 & 22 & 1.5 & 24.6 & 47.0 \\
\hline 23 & 32 & 4.5 & 18 & 3.0 & 15.8 & 14.7 \\
\hline 24 & 37 & 5.5 & 18 & 3.0 & 27.6 & 50.6 \\
\hline 25 & 37 & 4.5 & 22 & 1.5 & 32.7 & 51.4 \\
\hline 26 & 32 & 5.5 & 18 & 1.5 & 20.1 & 12.9 \\
\hline 27 & 42 & 5.5 & 22 & 1.5 & 23.6 & 56.8 \\
\hline
\end{tabular}

Table 2. Analysis of variance for S. lutetiensis and L. plantarum.

\begin{tabular}{|c|c|c|c|c|c|}
\hline \multirow{2}{*}{ Source } & \multicolumn{3}{|c|}{ S. lutetiensis } & \multicolumn{2}{|c|}{ L. plantarum } \\
\hline & DF & F-Value & $p$-Value & F-Value & $p$-Value \\
\hline Model & 14 & 2.31 & 0.077 & 7.00 & 0.001 \\
\hline Linear & 4 & 1.89 & 0.177 & 15.96 & 0.000 \\
\hline Temp & 1 & 0.01 & 0.911 & 62.51 & 0.000 \\
\hline $\mathrm{pH}$ & 1 & 1.59 & 0.232 & 0.34 & 0.569 \\
\hline Time & 1 & 6.97 & 0.022 & 0.39 & 0.546 \\
\hline Salt & 1 & 0.65 & 0.437 & 1.84 & 0.200 \\
\hline Square & 4 & 0.62 & 0.658 & 3.30 & 0.048 \\
\hline Temp $\times$ Temperature & 1 & 0.01 & 0.922 & 4.86 & 0.048 \\
\hline $\mathrm{pH} \times \mathrm{pH}$ & 1 & 1.51 & 0.243 & 2.63 & 0.131 \\
\hline Time $\times$ Time & 1 & 0.45 & 0.513 & 4.42 & 0.057 \\
\hline Salt $\times$ Salt & 1 & 1.03 & 0.330 & 2.55 & 0.136 \\
\hline 2-Way Interaction & 6 & 3.15 & 0.043 & 3.07 & 0.047 \\
\hline Temperature $\times \mathrm{pH}$ & 1 & 1.45 & 0.251 & 0.00 & 0.988 \\
\hline Temperature $\times$ Time & 1 & 0.38 & 0.550 & 0.16 & 0.695 \\
\hline Temperature $\times$ Salt & 1 & 9.07 & 0.011 & 0.18 & 0.678 \\
\hline $\mathrm{pH} \times$ Time & 1 & 0.00 & 0.980 & 0.59 & 0.457 \\
\hline $\mathrm{pH} \times$ Salt & 1 & 4.11 & 0.065 & 0.25 & 0.627 \\
\hline Time $\times$ Salt & 1 & 4.17 & 0.064 & 13.49 & 0.003 \\
\hline Error & 12 & & & & \\
\hline Lack-of-Fit & 9 & 1.84 & 0.335 & 1.92 & 0.321 \\
\hline Pure Error & 3 & & & & \\
\hline Total & 26 & & & & \\
\hline
\end{tabular}




\subsection{In Vitro Digestion by INFOGEST2.0 Model}

All samples of LAB strains were subjected to the in vitro gastrointestinal INFOGEST 2.0 protocol [22]. A $1 \mathrm{~mL}$ aliquot of the bacterial pellet suspension was subjected to in vitro digestion including oral phase (amylase $75 \mathrm{U} / \mathrm{mL}$, salivary fluid SSF, $0.3 \mathrm{M} \mathrm{CaCl}_{2}, 2 \mathrm{~min}$, $37^{\circ} \mathrm{C}$ ), gastric phase (pepsin $2000 \mathrm{U} / \mathrm{mL}$, gastric juice SGF pH 3.0, $0.3 \mathrm{M} \mathrm{CaCl}_{2}, 120 \mathrm{~min}$, $37^{\circ} \mathrm{C}$ ) without adding the rabbit gastric extract, and intestinal phase (pancreatin $100 \mathrm{U} / \mathrm{mL}$, bile $10 \mathrm{mmol} / \mathrm{L}$, duodenal juice SIF pH 7.0, $0.3 \mathrm{M} \mathrm{CaCl}_{2}, 120 \mathrm{~min}, 37^{\circ} \mathrm{C}$ ). Continuous shaking at $120 \mathrm{rpm}$ was employed during the in vitro digestion. During the process of INFOGEST 2.0, samples were collected for both bacterial count and acrylamide analysis. Serial dilution was used to measure the bacterial count directly after taking the samples. For acrylamide analysis, samples were kept frozen under $-20{ }^{\circ} \mathrm{C}$ until further analysis.

\subsection{Quantification of Acrylamide by LC-MS-MS}

The amount of acrylamide present in the aqueous fraction was determined by using the Agilent 1290 Infinity LC system equipped with MS/MS detector (Agilent, Santa Clara, CA, USA) using Column Hypercarb $C_{18}(2.1 \times 100 \mathrm{~mm}, 5.0 \mu \mathrm{m}$, Thermo Scientific, Waltham, MA, USA) with a mobile phase of $1 \%$ acetic acid in deionized water with a flow rate of $0.2 \mathrm{~mL} / \mathrm{min}$, an injection volume of $20 \mu \mathrm{L}$ and a column temperature of $35^{\circ} \mathrm{C}$. An external acrylamide standard curve of $0,5,10,25,50,75,100,125$ and $150 \mu \mathrm{g} / \mathrm{mL}$ was constructed for quantification.

\subsection{Understanding Mechanism of Acrylamide Binding by LAB}

2.7.1. Preparation of Samples and Binding Assay

The two strains of the LAB were activated twice in MRS broth for $24 \mathrm{~h}$ under $37^{\circ} \mathrm{C}$. An aliquot of the activated cultures from the second subculture's culture to obtain $10^{9} \mathrm{cfu} / \mathrm{mL}$ of the second subculture was added at $1 \% v / v$ to $10 \mathrm{~mL}$ of fresh MRS broth containing $10 \mu \mathrm{g} / \mathrm{mL}$ acrylamide and incubated under the following conditions: $37^{\circ} \mathrm{C}, 0 \% \mathrm{NaCl}$ and $\mathrm{pH} 6.5$ for $18 \mathrm{~h}$. After the incubation, samples were centrifuged under $5000 \times g, 10 \mathrm{~min}$, at $4{ }^{\circ} \mathrm{C}$. Supernatants were removed, and bacterial cells were collected in $0.1 \mathrm{M}, \mathrm{pH} 7.0$ phosphate buffer with $1.5 \mathrm{~mL}$ tubes and kept under $-20^{\circ} \mathrm{C}$ until analysis.

\subsubsection{Transmission Electron Microscopy (TEM) Measurement}

LAB cells were characterized by using Tecnai transmission electron microscopes (TEM) (FEI Company, Hillsboro, OR, USA) operating at $200 \mathrm{kV}$. When the samples were prepared (pre-fixed, rinsed, post-fixed, dehydrated, soaked, and embedded), they were cut into 50-60 nm thick sections by using Ultramicrotome-UC6 (Leica Microsystems GmbH, Wetzlar, Germany) [23].

\subsubsection{Estimation of Zeta Potential}

The zeta potential of the LAB cells was measured to test the stability of a colloid. A micro-electrophoretic apparatus Zeta Plus (Zetasizer Nano ZS 90, Malvern Instruments Ltd., Worcestershire, UK) was used to determine zeta potential. The experiment was performed at room temperature and the $\mathrm{pH}$ was adjusted using $0.1 \mathrm{M} \mathrm{NaOH}$ and $0.1 \mathrm{M} \mathrm{HCl}$ [23].

\subsubsection{Fourier Transform Infrared Spectroscopy (FTIR) Analysis}

FTIR analysis was conducted by attenuated total reflectance (ATR)-FTIR spectroscopy using a Spectrum Two IR coupled with a Universal ATR (UATR) unit (Perkin-Elmer Inc., Norwalk, CT, USA) to determine the functional groups and putative binding sites that would have an impact on acrylamide adsorption. Bacterial cell samples were freeze-dried and directly positioned on a Diamond/ZnSe crystal plate (Perkin-Elmer). The IR spectral range was $4000-400 \mathrm{~cm}^{-1}$ [23-25]. 
2.7.5. Scanning Electron Microscopy Coupled with Energy-Dispersive X-ray Spectroscopy (SEM-EDS)

SEM-EDS was performed to understand the morphology and elementary composition of bacterial cells. The bacterial cells were tested after adding acrylamide to the samples and were fixed with $2.5 \%(v / v)$ glutaraldehyde with $1 \%$ osmium tetroxide. S. lutetiensis and L. plantarum radius, height, and elemental composition were evaluated by Quanta 250 ESEM [24,26]. A $5 \mathrm{uL}$ amount of each sample was deposited on a piece of aluminum foil attached to the stainless-steel stub with carbon tape and allowed to dry before loading it into the SEM machine using a stub holder.

\subsection{Statistical Analysis}

To determine both mean values and standard deviations of results from screening of samples, Minitab v.21 (Minitab Ltd., Coventry, UK) was used. The BBD was performed, and the responses were analyzed using Minitab v.21.

\section{Results}

\subsection{Screening of Acrylamide Removal by $L A B$}

Figure 1 was used to assess the acrylamide removal ability in the screening stage. The conventional screening was used to examine the capability of LAB in binding to acrylamide. Acrylamide removal ranged from $3.1 \%$ to $39.1 \%$ (see Figure 1). The strains $S$. lutetiensis (39\%) and L. plantarum (26\%) had the highest acrylamide removal. It has been reported that acrylamide removal by microorganisms is species- and strain-dependent [7]. These two strains were selected for further study. Both strains Streptococcus lutetiensis and Lactiplantibacillus plantarum were certified as Generally Recognized as Safe by the US Food and Drug Administration [27]. Streptococcus lutetiensis strains are isolated from bovine and Lactiplantibacillus plantarum isolated from fermented food and dairy products. Streptococcus is commonly added to dairy, soy, and vegetable products in the food industry. Lactiplantibacillus plantarum is used to ferment cheese and other products [27].

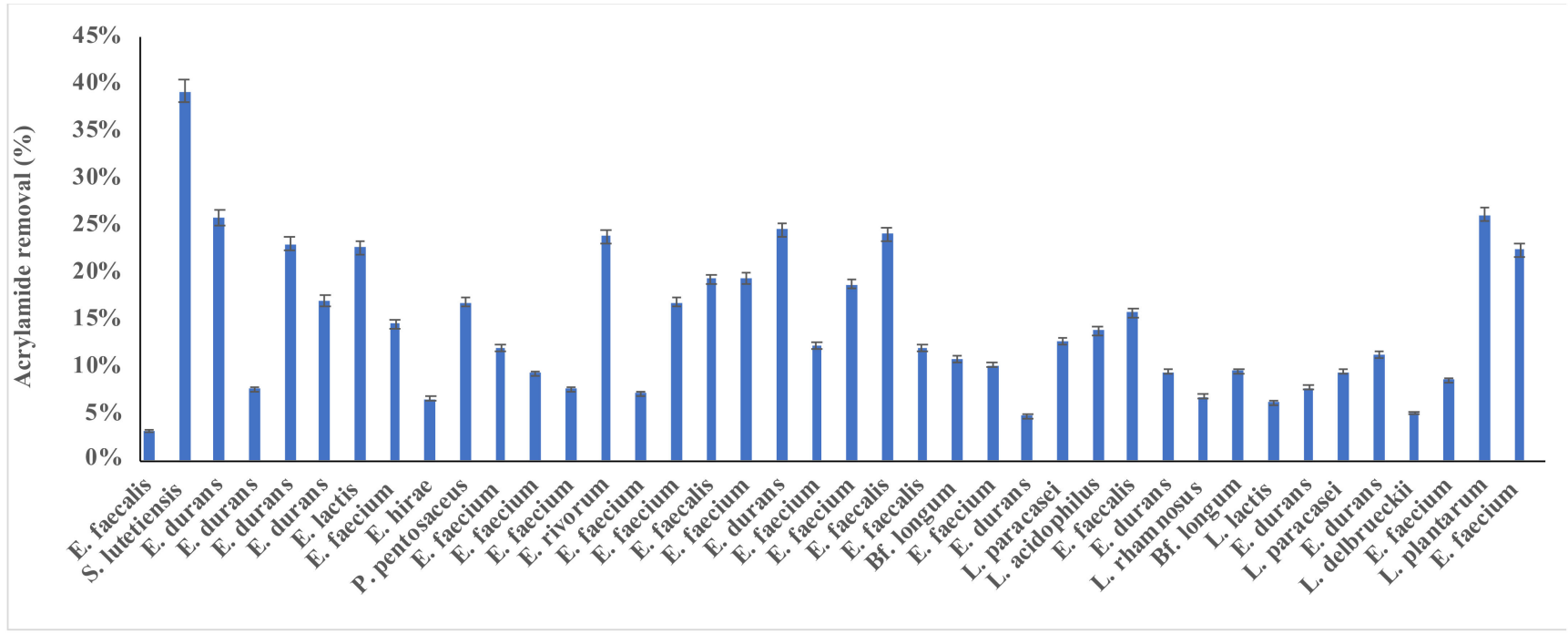

Figure 1. Acrylamide removal (\%) of 40 newly isolated lactic acid bacteria.

\subsection{Optimization of Acrylamide Removal}

Table 1 presents the results of the optimization of acrylamide removal by both $S$. lutetiensis and L. plantarum using BBD. Table 2 presents the analysis of variance for both strains. Figure 2A-L shows contour plots of the results of running the experiments using BBD. Based on the tested runs' results of S. lutetiensis and L. plantarum in Table 1, two 
regression equations are describing the true relationships between the responses and the independent variables for both strains as follows:

\section{Acrylamide removal}

$$
\begin{aligned}
& =713-9.9 X_{1}-101.6 X_{3}-134.6 X_{2}-11.8 X_{4}-0.001 X_{1}^{2}+4 X_{3}^{2}+0.131 X_{4}^{2}+1.62 X_{2}^{2} \\
& +1.22 X_{1} X_{3}+0.084 X_{1} X_{4}+1.633 X_{1} X_{2}+0.020 X_{3} X_{4}+6.39 X_{3} X_{2}+1.829 X_{4} X_{2}
\end{aligned}
$$

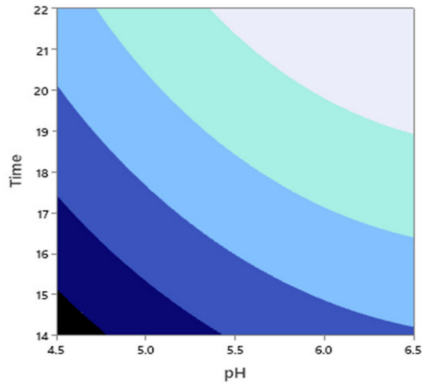

(A)

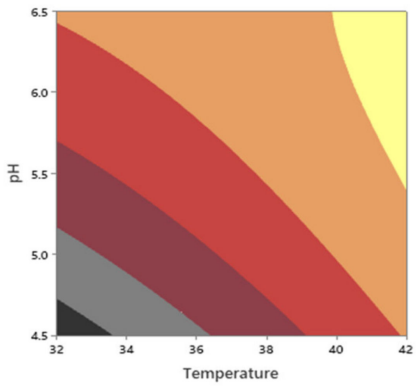

(D)

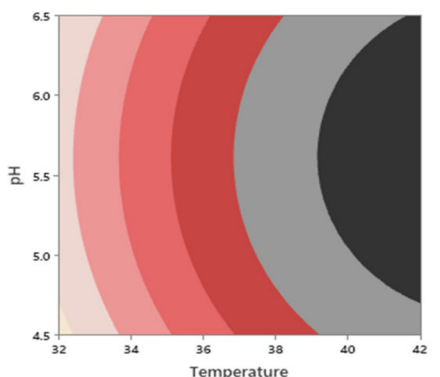

$(\mathrm{G})$

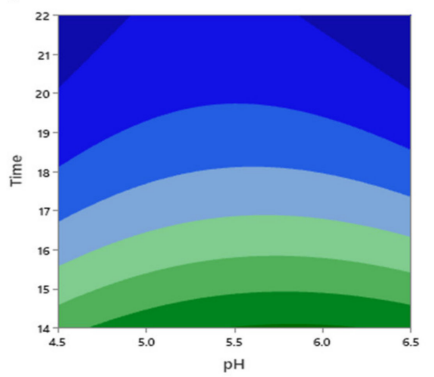

(J)
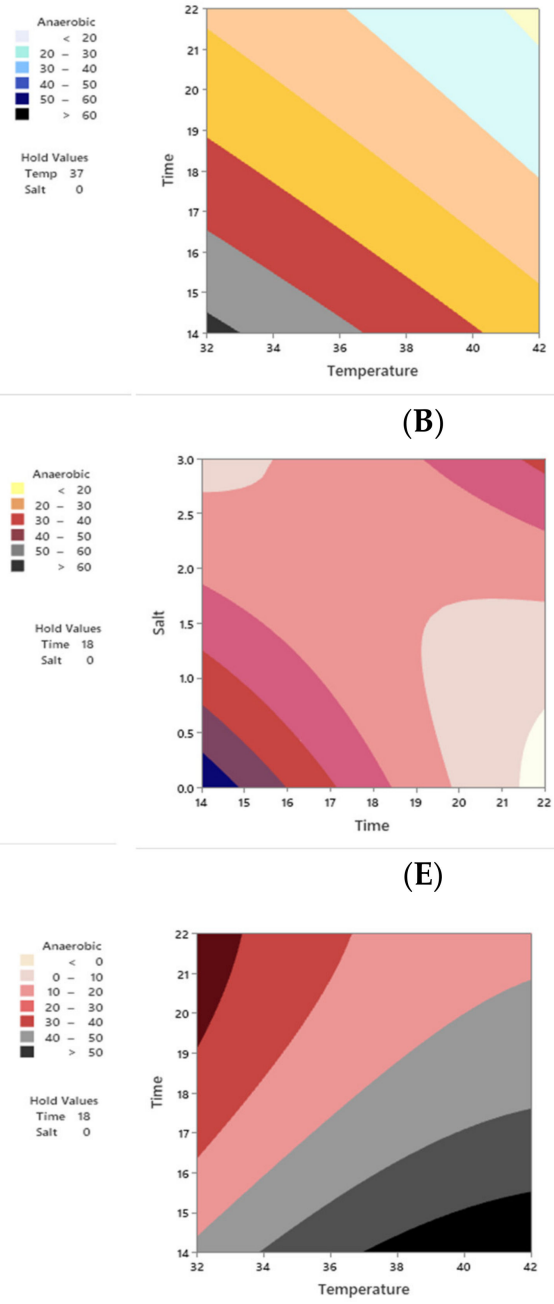

$(\mathbf{H})$
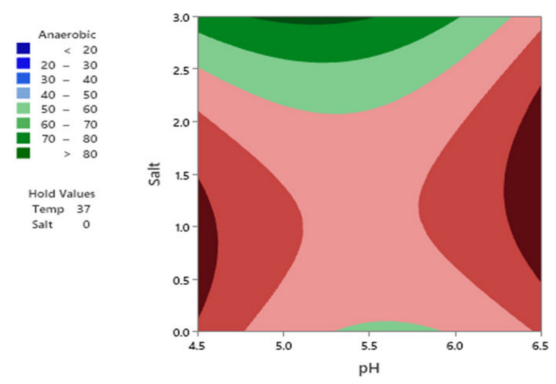

(K)

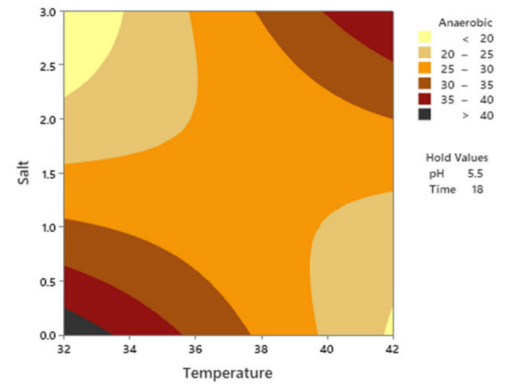

(C)

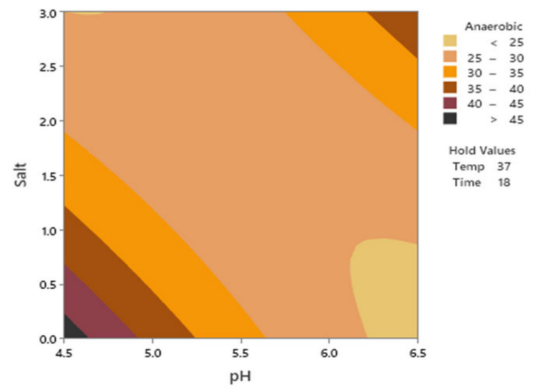

(F)
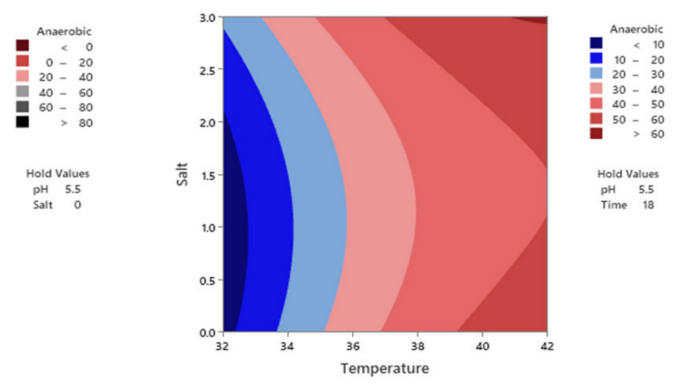

(I)
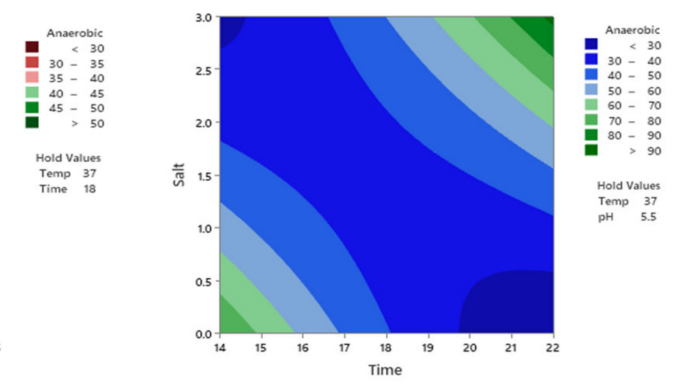

(L)

Figure 2. Contour plots of acrylamide removal in anaerobic conditions for S. lutetiensis (A-F) and $L$. plantarum (G-L) under controlled conditions of incubation time of $14-22 \mathrm{~h}$, salt $(\mathrm{NaCl})$ of $0.0-3.0 \%$, and incubation temperature of $32-42{ }^{\circ} \mathrm{C}$ and $\mathrm{pH}$ of $4.5-6.5$. 
(1) Regression equation in uncoded units of L. plantarum

Acrylamide removal

$$
\begin{aligned}
& =830-19.5 X_{1}-145 X_{3}-134.6 X_{2}-11.8 X_{4}-0.001 X_{1}^{2}+4 X_{3}^{2}+0.131 X_{4}^{2}+1.62 X_{2}^{2} \\
& +1.22 X_{1} X_{3}+0.084 X_{1} X_{4}+1.633 X_{1} X_{2}+0.020 X_{3} X_{4}+6.39 X_{3} X_{2}+1.829 X_{4} X_{2}
\end{aligned}
$$

After running analysis of variance (ANOVA) presented in Table 2, the statistically significant results were determined by $F$-value $=2.31$ and $p$-value was insignificant $(p>0.077)$ for $S$. lutetiensis, unlike L. plantarum, which showed statistically significant results of both $F$-value $=7.00$ and $p$-value of $(p<0.001)$.

The coefficient of determination values $\mathrm{R}^{2}$ was 0.72 for all models and suggested that the developed models have the goodness of fit that could explain $>72 \%$ of the total variation as presented in Supplementary Materials Table S1. The adjusted $R^{2}$ was $41.30 \%$ (Supplementary Materials Table S1) for S. lutetiensis. L. plantarum presented higher results and had the goodness of fit that could explain up to $89.09 \%$ of the total variation and the predicted $R^{2}$ value of $41.95 \%$. The $p$-values for the lack of fit for the models were not significant for both strains ( $p>0.335, p>0.321)$ of $S$. lutetiensis and L. plantarum, respectively.

For S. lutetiensis, Figure $2 \mathrm{~A}-\mathrm{F}$ shows the effect of salt and temperature at $\mathrm{pH}$ of 5.5 and incubation time $18 \mathrm{~h}$, where acrylamide was at its lowest level at $\mathrm{NaCl}$ of 0.0 and $32{ }^{\circ} \mathrm{C}$, and this relationship is statistically significant $(p<0.01)$. When $S$. lutetiensis was incubated under aerobic conditions, the bacterium showed different behaviors. The binding ability of the bacterium under the anaerobic conditions was better, by comparing Figures 1 and 2A-F.

There were no significant relationships between $\mathrm{pH}$, temperature, salt, and incubation time (Table 2). S. lutetiensis bound higher acrylamide amounts under anaerobic conditions. The rest of the factors were not significant, nor were their interactions (Table 2). By examining Figure 1, namely $\mathrm{pH}$ and temperature at $18 \mathrm{~h}$ and salt $(0.0)$, acrylamide was at its lowest level when the $\mathrm{pH}$ was at 4.5 and the temperature was at $32{ }^{\circ} \mathrm{C}$. By analyzing Figure $2 \mathrm{~A}-\mathrm{F}$ and studying the interaction of the factors with one another and their impact on $S$. lutetiensis binding abilities, the optimum conditions were: $\mathrm{NaCl}(0.0)$, time (14-18), $\mathrm{pH}(4.5-5.5)$, and temperature $\left(32-37^{\circ} \mathrm{C}\right)$, where acrylamide results were at their minimum levels.

The only significant relationship for L. plantarum was for time and salt $p<0.01$ ) (Table 2). Figure $2 \mathrm{~L}$ shows the incubation time of $14-22 \mathrm{~h}$ and salt of $0.0-3.0 \%$ under controlled conditions of $\mathrm{pH}(5.5)$ and temperature $\left(37^{\circ} \mathrm{C}\right)$, the highest reduction of acrylamide was obtained under incubation time of 14 and $22 \mathrm{~h}$ and salt of 0 and $3 \%$.

\subsection{Acrylamide Removal Under In Vitro Digestion}

The percentages of acrylamide removal were $35.1 \pm 1.22 \%$ and $41.2 \pm 2.32 \%$ for $L$. plantarum and S. lutetiensis, respectively. This indicates that acrylamide removal is speciesdependent. Our results imply that LAB could remove the formed acrylamide during in vitro digestion. To the best of our knowledge, this is the first report on acrylamide removal by $L A B$ during in vitro digestion. The effect of the matrix on acrylamide removal during in vitro digestion was also investigated. Our results showed that the media matrix (the in vitro digestion solutions) had a minor effect $(<1.1 \%)$ on acrylamide removal.

\subsection{Mechanisms of Acrylamide Removal \\ 3.4.1. Estimation of Zeta Potential of Bacterial Cells}

The average zeta potentials of $S$. lutetiensis and L. plantarum suspensions were -0.72 and $0.37 \mathrm{mV}$, respectively. Both strains showed excellent to maximum coagulation results, and both had high adsorption rates. The control sample, which had the bacteria without acrylamide, had a zeta potential of $-13.51 \mathrm{mV}$, which suggests that adding acrylamide to the bacterial samples might have had an impact on the zeta potential. Noting that $\mathrm{pH}$ is a major factor that affects zeta potential, it might be suggested that acrylamide changed the $\mathrm{pH}$ of the samples. 


\subsubsection{Fourier Transform Infrared Spectroscopy (FTIR) Analysis}

The FTIR spectra of S. lutetiensis and L. plantarum are presented in Figure 3A,B. The two strains showed different peaks comparing them to each other. The different peaks refer to the differences in the functional groups $(\mathrm{C}-\mathrm{O}, \mathrm{C}=\mathrm{O}$, and $\mathrm{N}-\mathrm{H})$, which might lead to the variations in adsorption capacities.

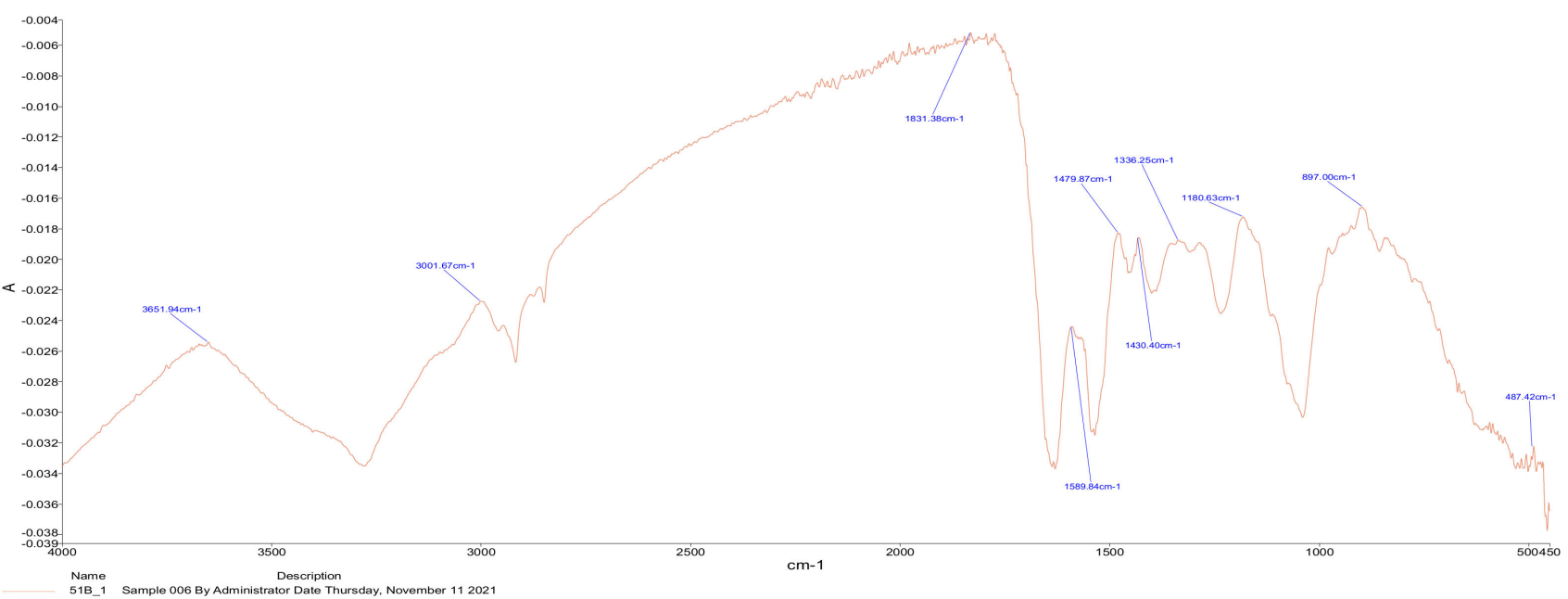

(A)

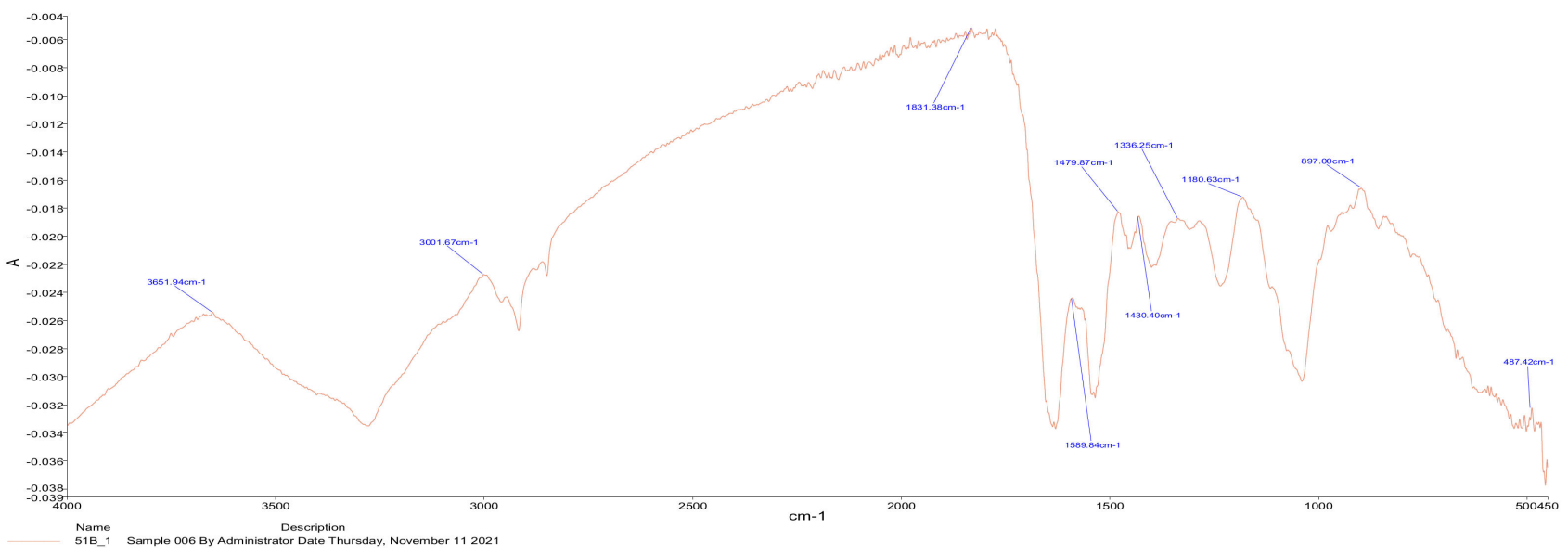

(B)

Figure 3. FTIR spectra of S. lutetiensis (A) and L. plantarum (B) label for (A,B).

3.4.3. Scanning Electron Microscopy Coupled with Energy-Dispersive X-ray Spectroscopy (SEM-EDS)

Figure $4 \mathrm{~A}-\mathrm{F}$ presents the elements of S. lutetiensis and L. plantarum. Figure $4 \mathrm{C}$ shows that the most dominant elements in S. lutetiensis were $\mathrm{C}, \mathrm{N}, \mathrm{O}, \mathrm{Al}, \mathrm{P}, \mathrm{Na}$, and $\mathrm{K}$, whereas $L$. plantarum had $\mathrm{Be}, \mathrm{C}, \mathrm{N}, \mathrm{O}, \mathrm{Na}, \mathrm{Mg}$, and $\mathrm{Al}$ in different atomic percentages. The control did not show atomic percentages of $\mathrm{O}, \mathrm{Na}, \mathrm{Mg}, \mathrm{Al}$, or $\mathrm{K}$, which might explain that acrylamide caused some changes in the chemical composition of the bacteria. S. lutetiensis and L. plantarum had significant differences in the composition of elements. Interestingly, Beryllium (Be) was found in a very high amount in L. plantarum and $\mathrm{P}$ and $\mathrm{K}$ lower than 0.05 atomic $\%$ (Figure $4 \mathrm{C}, \mathrm{F}$ ). The existence of the three atoms oxygen $(\mathrm{O})$, nitrogen $(\mathrm{N})$, and carbon (C) might also explain acrylamide adsorption because, in the case of the control, oxygen was zero. 


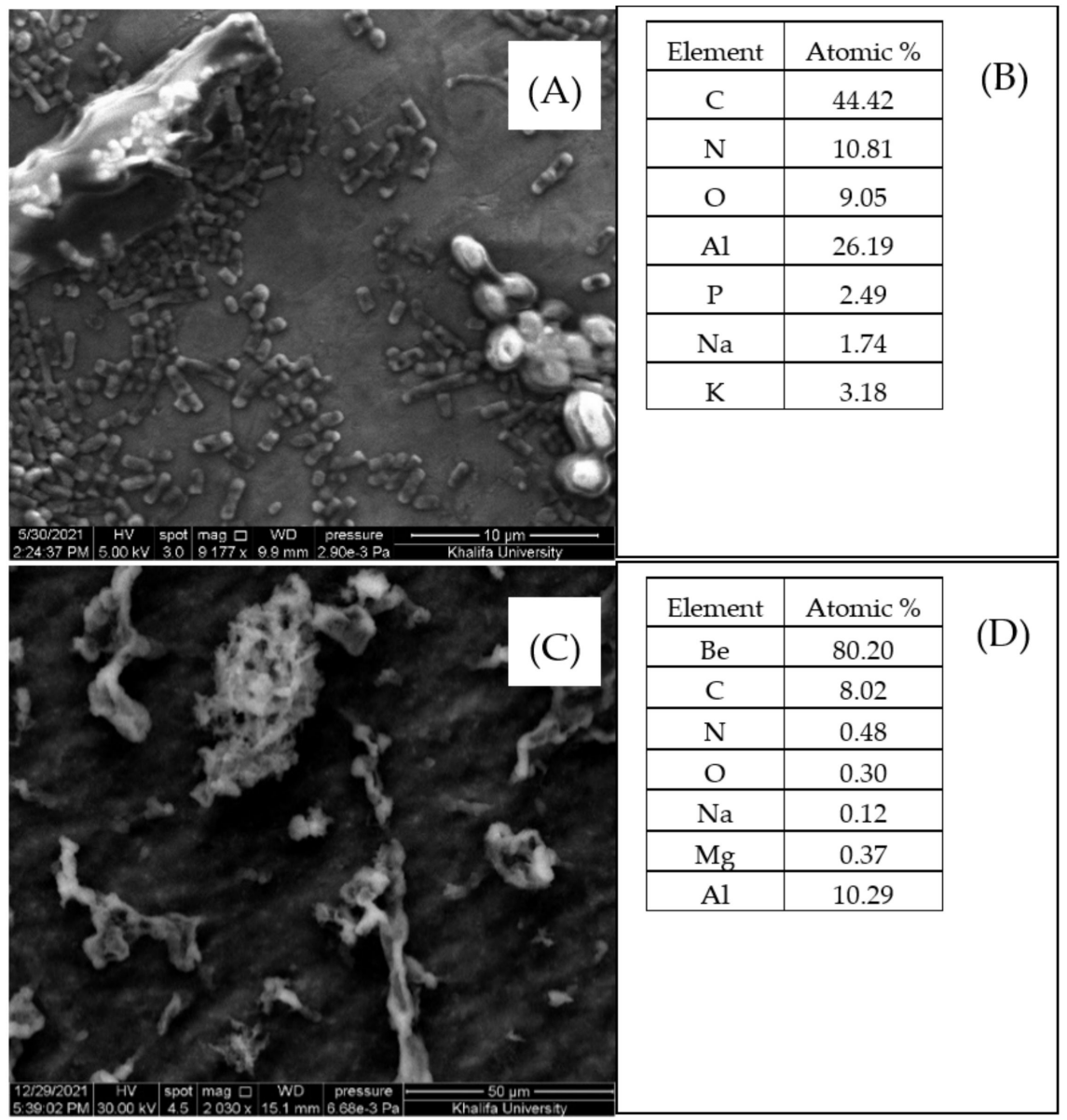

Figure 4. SEM-EDS images and elements of S. lutetiensis $(\mathbf{A}, \mathbf{B})$ and L. plantarum $(\mathbf{C}, \mathbf{D})$ and the peaks of the EDS of the main elements.

\subsubsection{Transmission Electron Microscopy (TEM) Measurement}

The TEM images of S. lutetiensis and L. plantarum are displayed in Figure 5. Based on the visual observations, the TEM images showed an increase in the cell wall thickness compared with the bacterial cells grown in MRS without acrylamide. This test was done for qualitative purposes and not for measuring the cell wall thickness.
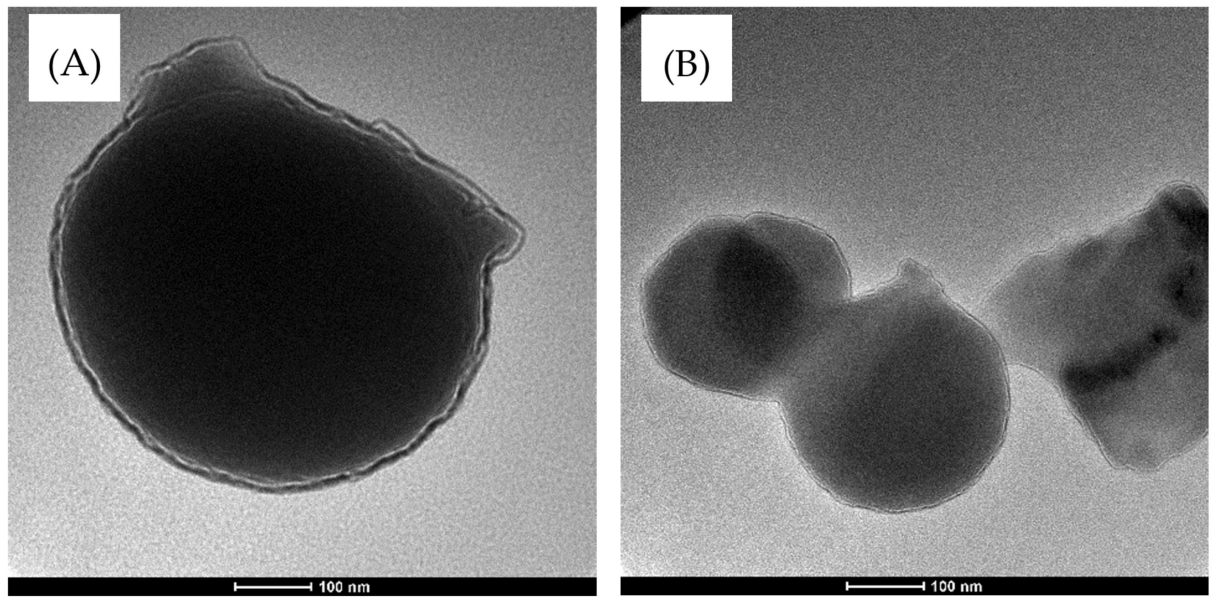

Figure 5. TEM of (A) S. lutetiensis and (B) L. plantarum showing the shape of the cells and the thickness of the cell walls. 


\section{Discussion}

Several new approaches have been employed by scientific researchers to reduce acrylamide and other toxins in food, at the industrial scale, and maintain the quality of the final products. Some LAB strains showed positive results. This research analyzed the ability of two strains out of forty. The latest studies published on LAB's ability to reduce acrylamide and toxins suggest that the following mechanisms are involved: adsorption, degradation, precursor reduction, or antioxidant properties that reduce the accumulation of amines and N-nitrosamines [2].

It is reported that Limosilactobacillus reuteri and Lacticaseibacillus casei Shirota could remove up to $24.01 \%$ and $24.95 \%$ of acrylamide, respectively, after $12 \mathrm{~h}$ of incubation in MRS broth. L. reuteri NRRL 14171 and L. casei Shirota had the highest binding capacity of acrylamide in a study of fourteen LAB [28]. All strains exhibited high stability after repeated washing and were $\mathrm{pH}$-dependent [28]. However, the current study revealed that under an uncontrolled environment, both S. lutetiensis and L. plantarum removed 39\% and $26 \%$ of acrylamide, respectively, while under controlled conditions the removal percentage increased up to $46 \%$ and $57 \%$, respectively.

LAB can also bind other toxins. For example, Lactobacillus johnsonji CECT 289 had the highest reduction of $97.4 \%$ removal of ochratoxin A in MRS among all the tested strains of LAB under gastrointestinal digestion [29]. In addition, strains of L. plantarum removed up to $47.80 \%$ of zearalenone [30]. The removal is affected by several factors like bacterial cells density, the concentration of the toxin, the viability of the bacteria, and incubation temperature. L. casei was found to have the ability to remove up to $49.2 \%$ of aflatoxin and tolerate bile salts [31]. L. plantarum had a significant binding ability with cadmium [32]. It also exhibited good anti-oxidative properties and resistance to simulated gastrointestinal conditions [32]. L. casei Shirota also exhibit good binding ability to remove up to $70 \%$ of acrylamide under different simulated gastrointestinal conditions [16]. These results indicate that adsorption capacity is strain- and bacterial count-dependent, which is in agreement with the results obtained herein $[23,24]$. It was recognized that the cell wall had a major role in the adsorption of acrylamide by LAB $[23,24]$. The present study indicated that cell wall components are crucial in acrylamide adsorption. SEM-EDS results showed significant changes in the wavenumbers of the $\mathrm{C}-\mathrm{O}, \mathrm{C}=\mathrm{O}$, and $\mathrm{N}-\mathrm{H}$, which are the functional groups in the $\mathrm{LAB}$ cell wall affecting acrylamide adsorption [33]. The present study demonstrated that $\mathrm{LAB}$ could remove acrylamide during in vitro digestion. This implies that the presence of LAB in food provides an additional safety margin against acrylamide. To the best of our knowledge, this study is the first attempt to investigate acrylamide removal by LAB under simulated GIT conditions (in vitro).

\section{Conclusions}

Overheating foods rich in carbohydrates might result in the formation of acrylamide, which is a carcinogenic chemical compound. Forty strains of lactic acid bacteria showed different acrylamide-binding abilities. Both S. lutetiensis and L. plantarum had the highest capability of acrylamide removal by $39 \%$ and $26 \%$, respectively. In a simulated intestinal tract system, both strains removed more than $30-40 \%$ of the acrylamide.

To understand the mechanism of acrylamide removal, lactic acid bacteria cells were characterized via scanning electron microscopy coupled with energy-dispersive $\mathrm{X}$-ray spectroscopy (SEM-EDS) and transmission electron microscopy (TEM) techniques. Cell charges were characterized by zeta potential and functional groups by Fourier transform infrared spectroscopy (FTIR). Results indicated that increasing cell wall thickness improves acrylamide adsorption capacity. Both FTIR and EDS indicated that functional groups $\mathrm{C}=\mathrm{O}, \mathrm{C}-\mathrm{O}$, and $\mathrm{N}-\mathrm{H}$ are associated with acrylamide adsorption. The results of both strains indicate that $\mathrm{LAB}$ can be used to eliminate acrylamide in gastrointestinal systems, but further studies are needed in vivo in the human being gastrointestinal system. 
Supplementary Materials: The following supporting information can be downloaded at: https: / / www.mdpi.com/article/10.3390/microorganisms10030557/s1, Table S1. Model Summary for Streptococcus lutetiensis and Lactobacillus plantarum.

Author Contributions: A.S.A., investigation, writing-original draft, formal analysis; R.A.S., and A.Y., investigation; T.M.O. and A.A.-N., supervising, writing-review and editing; S.-Q.L., writingreview and editing; G.P., supervision, writing-review and editing; M.M.A., conceptualization, writing — original draft, funding, supervising, writing—review and editing, supervision. All authors have read and agreed to the published version of the manuscript.

Funding: This research and APC were funded by the United Arab Emirates University (UAEU), Al-Ain, UAE.

Institutional Review Board Statement: Not applicable.

Informed Consent Statement: Not applicable.

Data Availability Statement: Not applicable.

Acknowledgments: The authors are very grateful to Dubai Central Laboratory and Khalifa University for their support. The authors are also thankful to the reviewers for their valuable comments.

Conflicts of Interest: The authors declare no conflict of interest.

\section{References}

1. International Agency for Research on Cancer. IARC monographs on the evaluation of carcinogenic risks to humans. In Some Industrial Chemicals; International Agency for Research on Cancer: Lyon, France, 1994; pp. 389-433.

2. $\mathrm{Wu}, \mathrm{B} . ;$ Chai, X.; He, A.; Huang, Z.; Chen, S.; Rao, P.; Ke, L.; Xiang, L. Inhibition of acrylamide toxicity in vivo by arginine-glucose maillard reaction products. Food Chem. Toxicol. 2021, 154, 112315. [CrossRef] [PubMed]

3. Mottram, S.D.; Wedzicha, B.L.; Dodson, A.T. Food chemistry: Acrylamide is formed in the Maillard reaction. Nature 2002, 419, 448. [CrossRef] [PubMed]

4. HEATOX Project. Guidelines to Authorities and Consumer Organisations on Home Cooking and Consumption; Food Quality and Safety: Oxford, UK, 2006.

5. Codex Alimentarius. Codex Alimentarius. Code of Practice for the Reduction of Acrylamide in Foods. In Prevention and Reduction of Food and Feed Contamination; CAC/RCP 67-2009; FAO: Rome, Italy, 2009.

6. European Food Safety Authority (EFSA). Scientific opinion on acrylamide in food: EFSA Panel on Contaminants in the Food Chain. EFSA J. 2015, 13, 4104.

7. Albedwawi, A.S.; Turner, M.S.; Olaimat, A.N.; Osaili, T.M.; Al-Nabulsi, A.A.; Liu, S.-Q.; Shah, N.P.; Ayyash, M.M. An overview of microbial mitigation strategies for acrylamide: Lactic acid bacteria, yeast, and cell-free extracts. LWT 2021, 143, 111159. [CrossRef]

8. Van Der Fels-Klerx, H.; Capuano, E.; Nguyen, H.; Mogol, B.A.; Kocadağlı, T.; Tas, N.; Hamzalığlu, A.; Van Boekel, M.; Gökmen, V. Acrylamide and 5-hydroxymethylfurfural formation during baking of biscuits: $\mathrm{NaCl}$ and temperature-time profile effects and kinetics. Food Res. Int. 2014, 57, 210-217. [CrossRef]

9. Xu, C.; Yagiz, Y.; Marshall, S.; Li, Z.; Simonne, A.; Lu, J.; Marshall, M.R. Application of muscadine grape (Vitis rotundifolia Michx.) pomace extract to reduce carcinogenic acrylamide. Food Chem. 2015, 182, 200-208. [CrossRef]

10. Xu, F.; Oruna-Concha, M.-J.; Elmore, J.S. The use of asparaginase to reduce acrylamide levels in cooked food. Food Chem. 2016, 210, 163-171. [CrossRef]

11. Zhang, X.; Zhang, M.; Adhikari, B. Recent developments in frying technologies applied to fresh foods. Trends Food Sci. Technol. 2020, 98, 68-81. [CrossRef]

12. Khorshidian, N.; Yousefi, M.; Shadnoush, M.; Siadat, S.D.; Mohammadi, M.; Mortazavian, A.M. Using probiotics for mitigation of acrylamide in food products: A mini review. Curr. Opin. Food Sci. 2020, 32, 67-75. [CrossRef]

13. Bartkiene, E.; Jakobsone, I.; Juodeikiene, G.; Vidmantiene, D.; Pugajeva, I.; Bartkevics, V. Study on the reduction of acrylamide in mixed rye bread by fermentation with bacteriocin-like inhibitory substances producing lactic acid bacteria in combination with Aspergillus niger glucoamylase. Food Control 2013, 30, 35-40. [CrossRef]

14. Bartkiene, E.; Jakobsone, I.; Pugajeva, I.; Bartkevics, V.; Zadeike, D.; Juodeikiene, G. Reducing of acrylamide formation in wheat biscuits supplemented with flaxseed and lupine. LWT 2016, 65, 275-282. [CrossRef]

15. Mousavinejad, G.; Rezaei, K.; Khodaiyan, F. Reducing acrylamide in fried potato pancake using baker's yeast, lactobacilli and microalgae. Qual. Assur. Saf. Crop. Foods 2015, 7, 779-787. [CrossRef]

16. Rivas-Jimenez, L.; Ramírez-Ortiz, K.; González-Córdova, A.; Vallejo-Cordoba, B.; Garcia, H.; Hernandez-Mendoza, A. Evaluation of acrylamide-removing properties of two Lactobacillus strains under simulated gastrointestinal conditions using a dynamic system. Microbiol. Res. 2016, 190, 19-26. [CrossRef] 
17. Zheng, J.; Wittouck, S.; Salvetti, E.; Franz, C.M.A.P.; Harris, H.M.B.; Mattarelli, P.; O'Toole, P.W.; Pot, B.; Vandamme, P.; Walter, J.; et al. A taxonomic note on the genus Lactobacillus: Description of 23 novel genera, emended description of the genus Lactobacillus Beijerinck 1901, and union of Lactobacillaceae and Leuconostocaceae. Int. J. Syst. Evol. Microbiol. 2020, 70, 2782-2858. [CrossRef]

18. Nematollahi, A.; Meybodi, N.M.; Khaneghah, A.M. An overview of the combination of emerging technologies with conventional methods to reduce acrylamide in different food products: Perspectives and future challenges. Food Control 2021, 127, 108144. [CrossRef]

19. Alkalbani, N.; Turner, M.; Ayyash, M.M. Isolation, identification, and potential probiotic characterization of isolated lactic acid bacteria and in vitro investigation of the cytotoxicity, antioxidant, and antidiabetic activities in fermented sausage. Microb. Cell Factories 2019, 18, 1-12. [CrossRef]

20. Ayyash, M.; Abushelaibi, A.; Al-Mahadin, S.; Enan, M.; El-Tarabily, K.; Shah, N. In-vitro investigation into probiotic characterisation of Streptococcus and Enterococcus isolated from camel milk. LWT 2017, 87, 478-487. [CrossRef]

21. Abushelaibi, A.; Al-Mahadin, S.; El-Tarabily, K.; Shah, N.P.; Ayyash, M. Characterization of potential probiotic lactic acid bacteria isolated from camel milk. LWT 2017, 79, 316-325. [CrossRef]

22. Brodkorb, A.; Egger, L.; Alminger, M.; Alvito, P.; Assunção, R.; Ballance, S.; Bohn, T.; Bourlieu-Lacanal, C.; Boutrou, R.; Carrière, F.; et al. INFOGEST static in vitro simulation of gastrointestinal food digestion. Nat. Protoc. 2019, 14, 991-1014. [CrossRef]

23. Shen, Y.; Zhao, S.; Zhao, X.; Sun, H.; Shao, M.; Xu, H. In vitro adsorption mechanism of acrylamide by lactic acid bacteria. LWT 2018, 100, 119-125. [CrossRef]

24. Ge, N.; Xu, J.; Peng, B.; Pan, S. Adsorption mechanism of tenuazonic acid using inactivated lactic acid bacteria. Food Control 2017, 82, 274-282. [CrossRef]

25. Lin, Z.; Ye, Y.; Li, Q.; Xu, Z.; Wang, M. A further insight into the biosorption mechanism of Au(III) by infrared spectrometry. BMC Biotechnol. 2011, 11, 98. [CrossRef]

26. Shen, Y.; Chen, G.; Li, Y. Effect of added sugars and amino acids on acrylamide formation in white pan bread. Cereal Chem. 2019, 96, 545-553. [CrossRef]

27. Alexandraki, V.; Tsakalidou, E.; Papadimitriou, K.; Holzapfel, W. Status and Trend of the Conservation and Sustainable Use of Micro-organism in Food Processes; FAO: Rome, Italy, 2013; p. 65.

28. Serrano-Niño, J.; Cavazos-Garduño, A.; González-Córdova, A.; Vallejo-Cordoba, B.; Hernández-Mendoza, A.; Garcia, H.S. In vitro Study of the Potential Protective Role of L actobacillus Strains by Acrylamide Binding. J. Food Saf. 2014, 34, 62-68. [CrossRef]

29. Luz, C.; Ferrer, J.; Mañes, J.; Meca, G. Toxicity reduction of ochratoxin A by lactic acid bacteria. Food Chem. Toxicol. 2018, 112, 60-66. [CrossRef] [PubMed]

30. Zhao, L.; Jin, H.; Lan, J.; Zhang, R.; Ren, H.; Zhang, X.; Yu, G. Detoxification of zearalenone by three strains of lactobacillus plantarum from fermented food in vitro. Food Control 2015, 54, 158-164. [CrossRef]

31. Hernández-Mendoza, A.; Garcia, H.S.; Steele, J.L. Screening of Lactobacillus casei strains for their ability to bind aflatoxin B. Food Chem. Toxicol. 2009, 47, 1064-1068. [CrossRef]

32. Zhai, Q.; Yin, R.; Yu, L.; Wang, G.; Tian, F.; Yu, R.; Zhao, J.; Liu, X.; Chen, Y.Q.; Zhang, H.; et al. Screening of lactic acid bacteria with potential protective effects against cadmium toxicity. Food Control 2015, 54, 23-30. [CrossRef]

33. Wang, L.; Yue, T.; Yuan, Y.; Wang, Z.; Ye, M.; Cai, R. A new insight into the adsorption mechanism of patulin by the heat-inactive lactic acid bacteria cells. Food Control 2015, 50, 104-110. [CrossRef] 